\title{
Sporidesmin Production and Sporulation in Pithomyces chartarum
}

\author{
By MARGARET E. Di MENNA, J. CAMPBELL AND P. H. MORTIMER \\ Ruakura Soil Research Station and Ruakura Animal Research Station, \\ Department of Agriculture, Hamilton, New Zealand
}

\author{
(Accepted for publication I6 December 1969)
}

\begin{abstract}
SUMMARY
Sporidesmin production by 37 recently isolated strains and one heavily sporing laboratory isolate of Pithomyces chartarum was assayed by toxicity in vitro to tissue culture cells and related to sporulation and growth. Under standard cultural conditions strains varied greatly in their ability to produce sporidesmin and spores. Heavily sporing cultures produced most sporidesmin and the level of sporidesmin production by a strain could be changed by manipulation of cultures in ways which also stimulated or depressed sporulation. Ultraviolet radiation increased sporulation and sporidesmin production in 33 strains. Shaken cultures, in which growth was good but sporulation suppressed, produced no sporidesmin. The close association of sporidesmin production with sporulation supports the reliability of spore counts as an index of pasture toxicity. Most and probably all strains of $P$. chartarum are potentially able to produce moderate to high levels of sporidesmin. Ultraviolet radiation may stimulate production of sporidesmin by the growing fungus but destroys it in aqueous solutions leached from the senescent mycelium.
\end{abstract}

\section{INTRODUCTION}

Strain variability in production of sporidesmin by Pithomyces chartarum (Berk. \& Curt.) M. B. Ellis was observed soon after this fungus, growing on pasture debris, was recognized as the cause of the mycotoxicosis of sheep and cattle called facial eczema (Percival \& Thornton, 1958). Ross \& Thornton (1962) and Ross (I962), using several strains, found that different isolates grown under similar conditions varied in the amount of sporidesmin they produced and that there was a general relationship between spore numbers and sporidesmin production. Dingley, Done, Taylor \& Russell (1962) using six strains, some of which did not spore freely, found more than hundredfold differences in amounts of sporidesmin produced under standard conditions. Davison \& Marbrook (1965), using ten strains which spored well in culture, found only sevenfold differences.

The following is an account of assay by toxicity in vitro to tissue culture cells of sporidesmin production by 38 strains of Pithomyces chartarum grown under various conditions. The relationship between sporidesmin production and sporulation was examined by manipulation of cultures in ways affecting sporulation; ultraviolet radiation was used to stimulate sporulation, shaken cultures to suppress it. A second purpose of the work was to determine the range of toxicities in a group of recently isolated strains in an attempt to find whether high and low toxin-producing strains occurred randomly in $P$. chartarum populations in the field, or whether strains of 
similar toxicity occurred together in time or place. A third was to select for routine sporidesmin production those strains which produced most sporidesmin on sterilized ryecorn, a medium more suitable for large scale extraction than broth or agar cultures.

For the reasons given by Mortimer \& Collins (I968) we assumed that virtually all the toxin assayed in the Pithomyces chartarum cultures was sporidesmin.

\section{METHODS}

\section{Strains used}

Thirty-seven of the 38 Pithomyces chartarum strains used were isolated between September 1966 and June 1968 during a survey of moulds on leaves of pasture plants (di Menna \& Parle, 1970). Nineteen were from samples collected in the Hamilton area and five from places on the East Coast of the North Island, $c$. I50 miles from Hamilton. Thirteen were from material collected from one place on one day, from Thames 40 miles from Hamilton, on I March 1967. Seven of the Hamilton strains were recovered in 1966 and 1967 during a period when field conditions were unfavourable for the growth of $P$. chartarum and only isolated cases of facial eczema occurred. The remaining 12 Hamilton strains were recovered in the first half of 1968 when there was a widespread facial eczema outbreak. The last strain used, c, a laboratory isolate from a heavily sporing sector of a culture isolated in 1958 , has been used for sporidesmin production.

Single spore isolates were used, except for a few very poorly sporing strains from which such preparations were not practicable. Primary cultures, from which subcultures were made for the preparation of inocula, were held in sterilized soil.

\section{Culture techniques}

Media. Semi-synthetic broth (SSB): Glucose, 20 g.; Difco yeast extract, 2 g.; Oxoid peptone, 2 g.; maltose, 2 g.; $\mathrm{NH}_{4} \mathrm{NO}_{3}, 2$ g.; $\mathrm{NaNO}_{3}, 2$ g.; $\mathrm{MgSO}_{4}, 2$ g.; $\mathrm{KH}_{2} \mathrm{PO}_{4}$, $2 \mathrm{~g}$.; distilled water I 1.; $\mathrm{pH}$ adjusted to $6 \cdot 5-7 \cdot 0$; sterilized by autoclaving for $\mathrm{I} 5 \mathrm{~min}$. at $\mathrm{I} 20^{\circ}$ (Bohner, Fetz, Harri, Sigg, Stoll \& Tamm, I965). Sterilized ryecorn: Ryecorn (Secale cereale), $75 \mathrm{~g}$. and distilled water, $45 \mathrm{ml}$./pint milk bottle; soaked overnight, sterilized by autoclaving for $30 \mathrm{~min}$. at $120^{\circ}$ (Done, Mortimer, Taylor \& Russell, 196I). Maintenance medium for dilution of culture filtrates: Tissue culture medium I99 (Burroughs Wellcome \& Co., London) with $5 \%$ pooled calf serum; $0.16 \%$ $\mathrm{NaHCO}_{3}$, penicillin (IOO units $/ \mathrm{ml}$.) and streptomycin (IOO $\mu \mathrm{g} . / \mathrm{ml}$.).

Preparation of cultures. SSB cultures to be irradiated and incubated in parallel in the dark were inoculated in bulk lots with suspensions of spores and hyphae and dispensed in $15 \mathrm{ml}$. quantities into disposable plastic Petri dishes $8.5 \mathrm{~cm}$. in diameter. Inoculated broth to be incubated on a rotary shaker in the dark and, in parallel, unshaken, was dispensed in $200 \mathrm{ml}$. quantities into $500 \mathrm{ml}$. Erlenmeyer flasks. Cultures for each treatment were set up in triplicate; one culture was used for sporidesmin assay, one for a spore count, and one for estimation of the dry weight of mycelium.

Ryecorn in ten bottle batches was inoculated with each strain, incubated in the dark, harvested, and mixed thoroughly before aliquots were taken for analysis.

All strains were cultured in SSB with and without ultraviolet (u.v.) radiation and in ryecorn. Three strains were used for shaken and static cultures.

Incubation temperature. Cultures were incubated at $20^{\circ}$, the optimum temperature 
for sporidesmin production on potato-carrot broth (Ross \& Thornton, 1962), and on propylene oxide sterilized ryegrass leaves (Davison \& Marbrook, I965).

Incubation times. SSB cultures in Petri dishes were routinely incubated for 2 weeks but, to follow the course of the production of sporidesmin and spores, three strains were grown with and without u.v. radiation and harvested after 3, 6, 9, I2 and I4 days incubation.

SSB shaken and static flask cultures were incubated for 4, 7 and 14 days. A further set was incubated on the shaker for 7 days and then static for 7 days. Collars of growth forming on the sides of the shaken flasks were loosened into the medium every second day.

Ryecorn cultures were incubated for 4 weeks. Preliminary work with strain $\mathrm{C}$ showed that there was a tenfold increase in sporidesmin content between the second and third week of incubation and a twofold increase between the third and fourth week, but only a slight increase between the fourth and fifth week.

Ultraviolet radiation. The fixture used was a fluorescent tube giving radiation at $350 \mathrm{~nm}$. mounted between two cool white fluorescent tubes at a distance of $12 \mathrm{in}$. above bench height. The plastic Petri dishes used were transparent to radiation of $295 \mathrm{~nm}$. or more. Cultures were irradiated for Io hr/day between the second and eighth incubation days, a total of $70 \mathrm{hr}$.

In addition, two strains incubated in SSB for I4 days were given u.v. radiation doses of 20-I30 hr. The effect of time of dosage was also examined. A total of $60 \mathrm{hr}$ u.v. radiation was given, either on the second to seventh incubation days or on the eighth to thirteenth days.

\section{Assay techniques}

Spore counts. SSB cultures from Petri dishes or flasks were first frozen and thawed to improve spore dispersal, then shaken with glass beads for $10 \mathrm{~min}$. on a wrist action shaker. The resultant spore suspension, diluted where necessary, was counted in a haemocytometer. One g. of ryecorn culture suspended in $10 \mathrm{ml}$. water was treated in the same way. Spores were counted in $2 \mathrm{cu}$. $\mathrm{mm}$. of each preparation.

Dry weight of mycelium. SSB cultures were centrifuged to remove excess broth and mycelial mats dried at $105^{\circ}$ for $24 \mathrm{hr}$ before weighing.

Sporidesmin assay. SSB cultures were homogenized for $30 \mathrm{sec}$. in a Sorval Omnimixer and vacuum filtered successively through Whatman no. 4I and no. I filter papers. The filtrates were then diluted to $10^{-2}$ with maintenance medium, sterilized by pressure filtration (Millipore G.S. $0.22 \mu$ ), and diluted decimally to $10^{-7}$. Noninoculated SSB was prepared similarly for assay controls.

Fifty g. of each ryecorn culture were weighed into a $500 \mathrm{ml}$. Erlenmeyer flask and shaken with $125 \mathrm{ml} .80 \%$ (v/v) methanol/water on a rotary shaker at $20^{\circ}$ for $20 \mathrm{hr}$. The extracts were vacuum filtered through paper as above, a $5 \mathrm{ml}$. portion from each diluted to $\mathrm{IO}^{-2}$ with maintenance medium, filter sterilized, and diluted decimally to $10^{-7}$.

To assay the relatively small amount of sporidesmin produced by some strains, $\mathrm{IO}^{-1}$ dilutions were prepared. For these $\mathrm{I} \mathrm{ml}$. portions of each extract were evaporated in vacuo in the dark. Each residue was dissolved in $0.1 \mathrm{ml}$. ethanol, the volume made up to Io ml. with maintenance medium, and sterilized by filtration. Previous work in this laboratory had shown that ethanol at $1 \%(\mathrm{v} / \mathrm{v})$ or less in water had no effect 
on the HEp2 cells in the culture system used, and in our study none of the test filtrates contained more than this. Non-inoculated ryecorn was extracted similarly and used as an assay control.

Tissue culture. Cells were cultured as described by Mortimer \& Collins (1968), who showed that a typical cytotoxic reaction was produced on HEp2 cell monolayers with a least recognizable toxic dose of $0.4 \mathrm{ng}$. sporidesmin $/ \mathrm{ml}$. In this investigation, solutions of purified crystalline sporidesmin of known concentration were tested at the same time as the Pithomyces chartarum culture filtrates and gave a typical reaction at a least toxic dose (1.t.d.) of $0.5 \mathrm{ng}$./1. All tubes were roller cultured and examined at 48 and $72 \mathrm{hr}$. Four tubes were used at the $10^{-1}$ dilution and $5^{-7}$ at all other dilutions.

The greatest dilution at which a definite cytotoxic dose was produced was taken to be the 1.t.d. and equivalent to $0.5 \mathrm{ng}$. sporidesmin $/ \mathrm{ml}$. The concentrations in the original SSB,culture or methanol extract of ryecorn were then calculated and expressed as mg. sporidesmin/l.

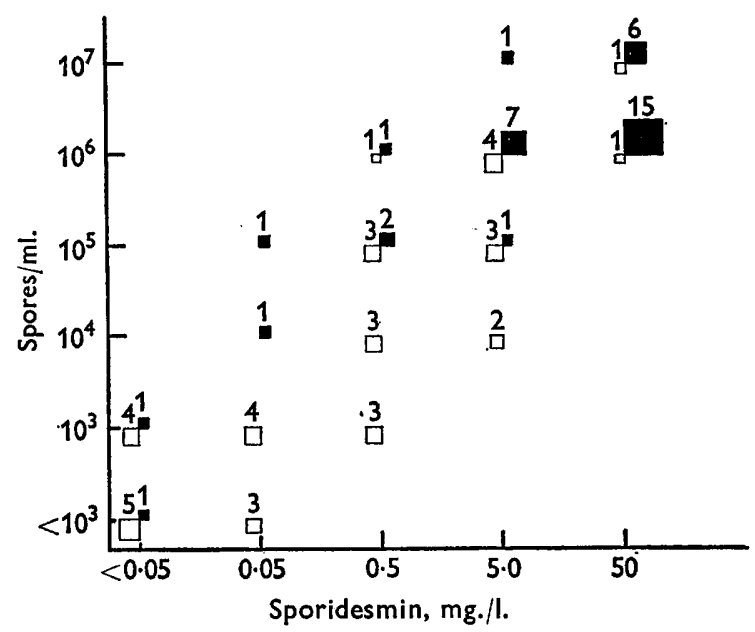

Fig. I. Relationship between sporidesmin concentration and spore numbers in 37 field strains of Pithomyces chartarum grown on SSB for I4 days at $20^{\circ}$ in the dark or with $70 \mathrm{hr}$ u.v. radiation. Numerals are number of strains at each level. $\square$, cultures incubated in the dark. $\mathbf{n}$, cultures given u.v. radiation.

\section{RESULTS}

SSB cultures

Effect of u.v. radiation. The effect of $70 \mathrm{hr}$ u.v. radiation on production of spores and sporidesmin in I4-day SSB Petri dish cultures is shown in Fig. I. Without u.v. radiation only II field strains produced 5 or more $\mathrm{mg}$. sporidesmin/l. With u.v. radiation 30 produced sporidesmin at this level, 18 producing $50 \mathrm{mg}$. $/ 1$. and three producing an amount in excess of 50 but less than $500 \mathrm{mg}$./1. Spore numbers were similarly affected; u.v. radiation increasing the number of strains producing $10^{6}$ or more spores $/ \mathrm{ml}$. from seven to thirty. There was a general but not exact relationship between sporidesmin production and spore numbers. A few cultures produced low levels of sporidesmin with no spores, or few spores but no detectable sporidesmin.

Strain $\mathrm{c}$ and four field strains were not affected by u.v. radiation. Strain c produced 
sporidesmin at a level of more than 50 but less than $500 \mathrm{mg} . / 1$. and $5 \times 10^{6} \mathrm{spores} / \mathrm{ml}$. in both irradiated and non-irradiated cultures. Two field strains also had high sporidesmin levels and spore counts in both sets of cultures, and two produced few or no spores and no detectable sporidesmin.

The dry weight of mycelium produced varied with strain, in non-irradiated SSB cultures from 0.82 to $\mathrm{I} \cdot 62$ (mean value $\mathrm{I} \cdot 26$ ) g./ $100 \mathrm{ml}$. of medium. In irradiated cultures the yield was always less, from 0.62 to $\mathrm{I} \cdot 19$ (mean value $\mathrm{I} \cdot 02$ ) $\mathrm{g}$./100 $\mathrm{ml}$.
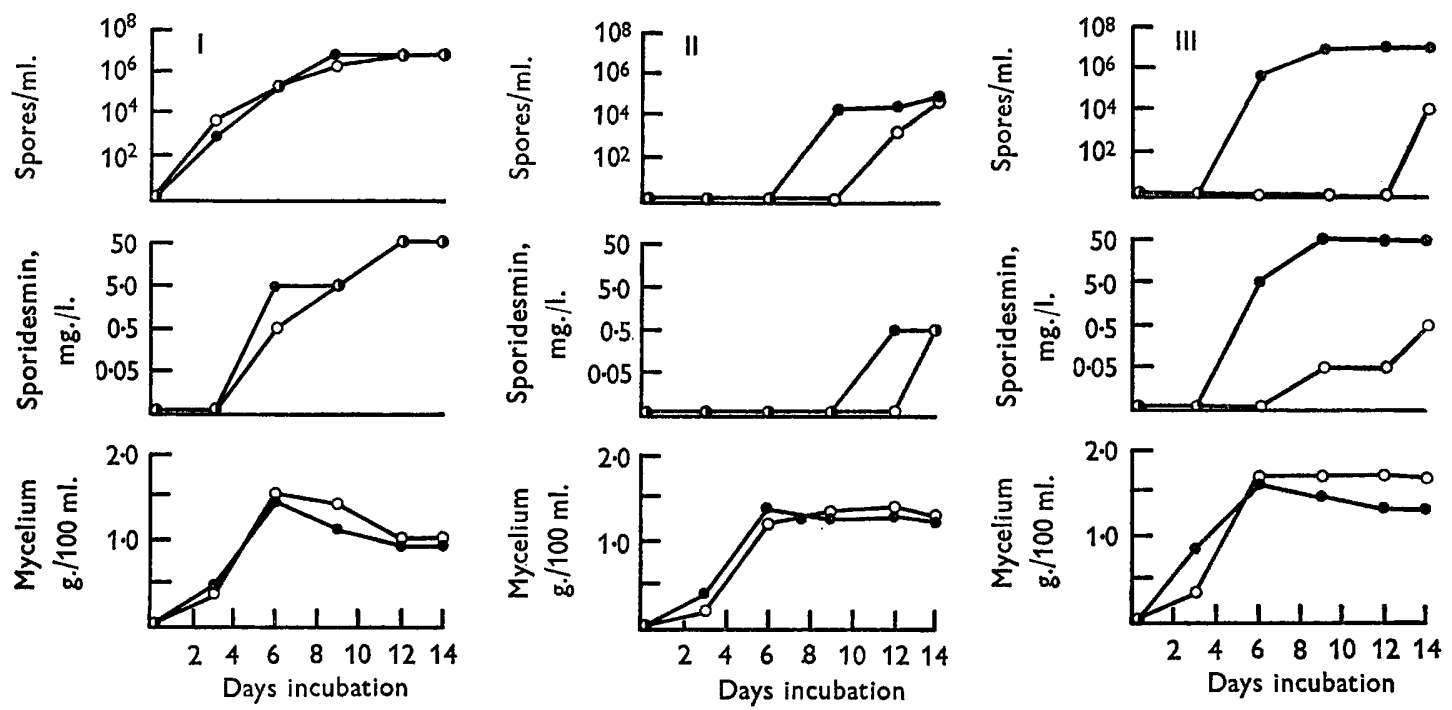

Fig. 2. Rate of production of sporidesmin, spores and dry weight of mycelium by three strains of Pithomyces chartarum grown on SSB at $20^{\circ}$. $\bigcirc-0$ incubated in dark. given to hr daily doses of u.v. radiation from the second to eighth incubation days inclusive. I, strain C; II, strain Ws(I) 1367 ; III, strain 2R(I5) 4468 .

Times at which sporidesmin and spores were produced in SSB Petri dish cultures varied with strain and treatment (Fig. 2). The maximum dry weight of mycelium was reached after 6 days incubation; subsequent to this it remained constant or decreased a little. Sporidesmin production was not related to growth for it was first detected after periods of from 6 to 14 days, after, before or at the same time that spores were first seen.

The effect of increasing doses of u.v. radiation upon two strains is shown in Table I. Twenty hr radiation had little effect on sporidesmin or spore production but reduced the dry weight of mycelium. Forty to $60 \mathrm{hr}$ exposure gave the maximum increase in production of sporidesmin and spores, and after this the response did not change.

Whether u.v. radiation was given in the first week of incubation when the mycelium was growing actively, or in the second week when the dry weight was no longer increasing, did not alter the final quantity of sporidesmin or spores produced by the two strains examined (Table 2).

Shaken and static cultures. Results from these are given in Table 3. Sporidesmin and spore production were both less in the SSB static flask cultures than in the same strains in the shallower Petri dish cultures. Growth also was less and after I4 days 
Table $\mathrm{r}$. Effect of increasing doses of u.v. radiation on sporidesmin production, spore numbers and dry weight of mycelium by two strains of Pithomyces chartarum grown on $S S B$ for 14 days at $20^{\circ}$

Radiation was begun on the second incubation day and given in $\mathrm{Io} \mathrm{hr}$ doses. There was no change in response to dosage at $70-130 \mathrm{hr}$ so these values are not given.

\begin{tabular}{|c|c|c|c|c|c|c|}
\hline \multirow[b]{2}{*}{$\begin{array}{l}\text { U.v. radiation } \\
\text { dosage }\end{array}$} & \multicolumn{3}{|c|}{ Strain $6 \mathrm{~L}$ I 7167} & \multicolumn{3}{|c|}{ Strain $R_{2}(39) 22568$} \\
\hline & $\begin{array}{l}\text { Spori- } \\
\text { desmin } \\
(\mathrm{mg} . / 1 .)\end{array}$ & Spores/ml. & $\begin{array}{c}\text { Dry wt } \\
\text { mycelium } \\
\text { (g./100 ml.) }\end{array}$ & $\begin{array}{l}\text { Spori- } \\
\text { desmin } \\
\text { (mg./1.) }\end{array}$ & Spores/ml. & $\begin{array}{c}\text { Dry wt } \\
\text { mycelium } \\
\text { (g./100 ml.) }\end{array}$ \\
\hline o hr & 0.5 & 70,000 & $I \cdot 6 I$ & 0.5 & II, 000 & $1 \cdot 62$ \\
\hline 20 & 0.5 & 200,000 & $I \cdot 33$ & 0.5 & $1,000,000$ & I.09 \\
\hline 40 & 50 & $2,000,000$ & $x \cdot 19$ & 50 & $7,000,000$ & 1.03 \\
\hline 50 & 50 & $4,000,000$ & $I \cdot I I$ & 50 & $8,000,000$ & $x \cdot 23$ \\
\hline 60 & 50 & $8,000,000$ & $\mathrm{I} \cdot 06$ & 50 & $9,000,000$ & $I \cdot 23$ \\
\hline 70 & 50 & $10,000,000$ & $r \cdot 00$ & 50 & $8,000,000$ & $I \cdot 22$ \\
\hline
\end{tabular}

Table 2. Effect of time of u.v. radiation dose on sporidesmin production, spore numbers and dry weight of mycelium by two strains of Pithomyces chartarum grown on SSB for 14 days at $20^{\circ}$

U.v. radiation was given in Io $\mathrm{hr}$ doses, on the 2 nd to 7 th incubation days during the Ist week, on the 8th to 13 th during the 2 nd week.

\begin{tabular}{|c|c|c|c|c|c|c|}
\hline \multirow[b]{2}{*}{$\begin{array}{l}\text { U.v. radiation } \\
\text { dosage }\end{array}$} & \multicolumn{3}{|c|}{ Strain 6L I 7 I67 } & \multicolumn{3}{|c|}{ Strain NB(I0) 1367} \\
\hline & $\begin{array}{l}\text { Spori- } \\
\text { desmin } \\
\text { (mg./1.) }\end{array}$ & Spores $/ \mathrm{ml}$. & $\begin{array}{c}\text { Dry wt } \\
\text { mycelium } \\
\text { (g./100 ml.) }\end{array}$ & $\begin{array}{l}\text { Spori- } \\
\text { desmin } \\
(\mathrm{mg} . / 1 .)\end{array}$ & Spores $/ \mathrm{ml}$. & $\begin{array}{c}\text { Dry wt } \\
\text { mycelium } \\
(\mathrm{g} . / 100 \mathrm{ml} .)\end{array}$ \\
\hline $\mathrm{o} \mathrm{hr}$ & 0.5 & 200,000 & $I \cdot 60$ & 0.5 & 70,000 & $\mathbf{I} \cdot 59$ \\
\hline $\begin{array}{c}60 \mathrm{hr} \\
\text { (Ist week) }\end{array}$ & 50 & $10,000,000$ & $I \cdot 09$ & 50 & $10,000,000$ & $\mathrm{I} \cdot 08$ \\
\hline $\begin{array}{c}60 \mathrm{hr} \\
\text { (2nd week) }\end{array}$ & 50 & $10,000,000$ & $I \cdot 3 I$ & 50 & $9, \infty 00, \infty 00$ & $I \cdot 23$ \\
\hline
\end{tabular}

Table 3. Sporidesmin, spores and dry weight of mycelium produced in shaken and static SSB cultures of three strains of Pithomyces chartarum

Treatment...

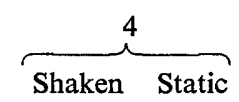

Days incubated...

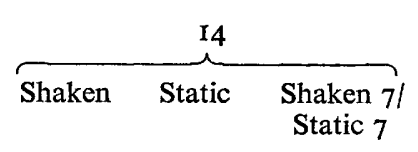

Strain C

Sporidesmin (mg./1.)

Spores $/ \mathrm{ml}$.

Dry wt (g./100 ml.)

Strain wS(I) I367

Sporidesmin (mg./1.)

Spores $/ \mathrm{ml}$.

Dry wt (g./100 ml.)

Strain 2R (I5) 4468

Sporidesmin (mg./1.)

Spores/ml.

Dry wt (g./100 ml.)

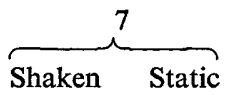

$\begin{array}{cc}0 & 0 \\ 0 & 5,000 \\ 0.71 & 0.19\end{array}$

$\begin{array}{cc}0 & 5.0 \\ 0 & 400,000 \\ 1 \cdot 36 & 0.56\end{array}$

0
0
0.72

0
0
0.60

500

0.74

$5 \cdot 0$
100,000

$\begin{array}{cc}0 & 0 \\ 0 & 0 \\ 0.70 & 0.07\end{array}$

$\begin{array}{cc}0 & 0 \\ 0 & 0 \\ I \cdot 15 & 0.23\end{array}$

$\begin{array}{ccc}0 & 0 & 0 \\ 0 & 0 & 0 \\ 0.37 & 0.14 & 1 \cdot 34\end{array}$
0
0.36

$\begin{array}{cc}0 & 0 \\ 0 & 0 \\ 0.43 & 0.69\end{array}$

$0.5 \quad 0.05$

00 
had not reached the maximum yield to be expected. In shaken cultures growth was good and reached a maximum in 7 days; there was considerable decline in dry weight by the I4th incubation day. Spores and sporidesmin were not produced in shaken cultures, but both sporidesmin and spores were present in cultures shaken for seven days and then held static for seven.

\section{Ryecorn cultures}

Strain c produced more than 50 but less than $500 \mathrm{mg}$. sporidesmin/l. of methanol extract of ryecorn culture, more than any of the field strains examined, and remains

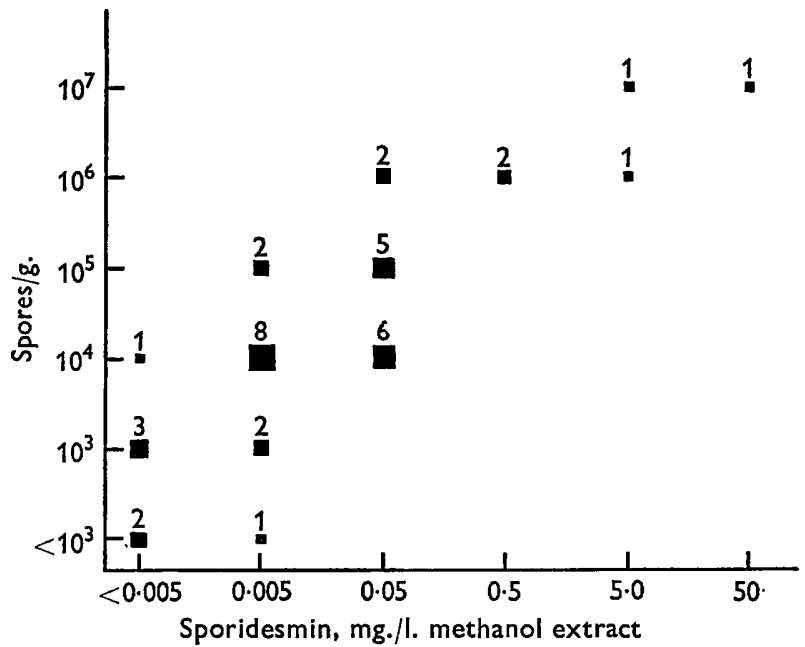

Fig. 3. Relationship between sporidesmin concentration and spore numbers in 37 field strains of Pithomyces chartarum grown on ryecorn for 4 weeks at $20^{\circ}$. Numerals are number of strains at each level.

Table 4. Sporidesmin production and spore numbers on ryecorn and SSB in 13 strains of Pithomyces chartarum isolated on I March 1967 from a site at Thames

Sporidesmin is measured in mg./l. of methanol extract of ryecorn culture, in mg./l. of SSB.

\begin{tabular}{lccccrrr} 
& \multicolumn{2}{c}{ Sporidesmin (mg./l.) } & \multicolumn{3}{c}{ Spores/g. or ml. of medium } \\
Strain & $\overbrace{\text { Ryecorn }}$ & SSB & SSB+u.v.r. & $\overbrace{\text { Ryecorn }}$ & SSB & SSB+u.v.r. \\
NB(7) & 0.5 & 0.05 & 0.5 & $10^{6}$ & 9,000 & $1,000,000$ \\
NB(8) & 0.005 & 0.05 & 0.05 & 0 & 0 & 70,000 \\
NB(9) & 0.005 & 0.05 & 0.05 & $10^{5}$ & 0 & 300,000 \\
NB(IO) & 0.005 & 5 & 50 & $10^{4}$ & 200,000 & $8,000,000$ \\
NB(I6) & 0.05 & 0.5 & 50 & $10^{4}$ & 200,000 & $9,000,000$ \\
NB(22) & 0.05 & 0.05 & 5 & $10^{5}$ & 3,000 & $4,000,000$ \\
NB(27) & 0.005 & 0.5 & 5 & $10^{4}$ & 1,000 & $2,000,000$ \\
NL(4) & 0.005 & 0.05 & 0.5 & $10^{5}$ & 0 & 500,000 \\
NL(I4) & 0.005 & 0.5 & 5 & 0 & 200,000 & $1,000,000$ \\
WL(I0) & 50 & 50 & 50 & $10^{7}$ & $10,000,000$ & $6,000,000$ \\
WB(I) & 5 & 0.5 & 50 & $10^{6}$ & 100,000 & $8,000,000$ \\
WB(27) & 0.05 & 0.5 & 5 & $10^{5}$ & 2,000 & $7,000,000$ \\
WS(I) & 0.005 & 50 & 50 & $10^{4}$ & $1,000,000$ & $1,000,000$
\end{tabular}


the most suitable isolate for routine sporidesmin production. Only one field strain produced $50 \mathrm{mg}$. $/ 1$., the majority 0.05 to $0.005 \mathrm{mg}$. $/ 1$., and six no detectable sporidesmin,

Spore counts varied from $10^{8} / \mathrm{g}$. of culture in strain $\mathrm{C}$ to less than $5000 / \mathrm{g}$. in three field strains. Sporidesmin production is plotted against spore numbers in Fig. 3 and, as with the SSB cultures, there is a general relationship between spore numbers and amount of sporidesmin produced. Four strains produced no detectable sporidesmin but $\mathrm{IO}^{3-4}$ spores/g. and one strain produced no spores but $0.005 \mathrm{mg}$. sporidesmin/l.

Strain response to treatment. Sporidesmin and spore production by 13 strains of Pithomyces chartarum isolated on I March 1967 from a site near Thames is given in Table 4. Each strain responded differently to culture on ryecorn and on SSB with and without u.v. radiation. From the data available the pattern of response of a strain was not predictable. Proportions of high and low sporidesmin and spore producers on the different treatments were the same in this group of isolates as in the whole range examined. There was no evidence that strains of similar toxicity occurred together in one place at one time.

\section{DISCUSSION}

Done, Mortimer, Taylor \& Russell (I96I), Ross \& Thornton (1962), Ross (I962), Dingley et al. (1962) and Davison \& Marbrook (1965) measured sporidesmin production by a number of strains of Pithomyces chartarum. Because there were differences in the media, incubation times and temperatures, and in the methods of sporidesmin assay used by each group, including the present authors, the absolute values for sporidesmin production are not comparable and the relative toxities of strains used by different workers cannot be determined. However, there was almost always a general relationship between the number of spores in a culture and the amount of sporidesmin present. There were two exceptions. A freely sporing American strain of $P$. chartarum produced no detectable sporidesmin (Brook \& Matthews, 1960; Ross \& Thornton, 1962). Two strains, $\mathrm{C}$ and s73a, grown in shaken potato-carrot broth for 4 days at $25^{\circ}$ produced 0.3 and $\mathrm{I} \cdot 5 \mathrm{mg}$. sporidesmin/l. respectively, but also some spores (Dingley et al. 1962). The sporidesmin produced under these conditions had disappeared by the seventh incubation day, and four other strains grown under similar conditions produced neither spores nor sporidesmin.

In the present work production of sporidesmin could not be dissociated from sporulation. Although the relationship between sporidesmin levels and spore numbers within a culture was not strictly quantitative, cultures which contained many spores had moderate to high sporidesmin levels and cultures with few spores contained little or undetectable sporidesmin. Within strains, u.v. radiation increased sporidesmin production where it increased sporulation; sporidesmin and sporulation were both suppressed in shaken cultures, and sporidesmin was first detectable in cultures at about the time that spores were produced. The association of sporidesmin with sporulation, although not exact, was sufficiently close to support the view that spore counts in herbage samples are a reliable index of pasture toxicity.

The way in which the level of sporidesmin production could be modified by the limited and somewhat arbitrary treatments used here suggests that strains may not have characteristically high or low sporidesmin producing potentials but rather may vary in the conditions under which they produce most sporidesmin. There was no 
evidence in this work that proportions of high to low toxin producing strains in field populations of Pithomyces chartarum varied with time or place. At all events it now appears more significant that sporidesmin production is much influenced by the chemical and physical state of the environment. In the field, substrate, temperature, humidity and ultraviolet dosage vary, within limits, with time and place. Conditions would favour, sporidesmin production now by one strain and now by another.

Two of the strains examined produced little or no sporidesmin and few spores with any treatment used. It is possible that in any cirumstances they would be weakly toxic but probable that under some cultural conditions they would produce sporidesmin at a moderate level at least. In this work it was not practicable to fit incubation period to strain, although it was known that time taken to produce spores varies greatly with strain, from two days to over a month under standard, apparently most favourable, conditions, and it is reasonable to assume that variation in time of sporidesmin production would be of the same order. Another important factor not examined was the effect on production of sporidesmin and spores of the fluctuations in temperature and humidity normal to pasture.

Turning to the practical importance of u.v. radiation, irradiation increases the rate of destruction of sporidesmin in aqueous solution (Clare \& Gumbley, I962; Clare \& Mortimer, 1964). In the field the interplay between the stimulation by u.v. radiation of fungal production of sporidesmin and the destructive effect of u.v. radiation on aqueous sporidesmin solutions must be considered. The stimulatory role would result in rapid build up of spores and sporidesmin in pasture when other conditions were optimal. The destructive role would hasten the loss of pasture toxicity when conditions for growth became less favourable.

\section{REFERENCES}

Bohner, B., Fetz, E., Harri, E., Sigg, H. P., Stoll, C. \& Tamm, C. (1965). Über die Isolierung von Verrucarin H, Verrucarin J, Roridin D und Roridin E aus Myrothrecium-arten. Helvetica Chimica Acta 48, 1079.

Brook, P. J. \& MATthews, R. E. F. (1960). The production of ${ }^{35}$ S labelled sporidesmin. New Zealand Journal of Science 3, 59I.

Clare, N. T. \& Gumbley, J. M. (1962). Some factors which may affect the toxicity of spores of Pithomyces chartarum (Berk. \& Curt.) M. B. Ellis collected from pasture. New Zealand Journal of Agricultural Research 5, 36.

Clare, N. T. \& Mortimer, P. H. (1964). The effect of mercury arc radiation and sunlight on the toxicity of water solutions of sporidesmin to rabbits. New Zealand Journal of Agricultural Research 7, 258.

Davison, S. \& Marbrook, J. (1965). The effect of temperature on the toxicity of spores of Pithomyces chartarum (Berk. \& Curt.) M. B. Ellis. New Zealand Journal of Agricultural Research 8, I26.

Dingley, J. M., Done, J., TAYloR, A. \& Russell, D. W. (1962). The production of sporidesmin and sporidesmolides by wild isolates of Pithomyces chartarum in surface and in submerged culture. Journal of General Microbiology 29, 127.

Done, J., Mortimer, P. H., TAylor, A. \& Russell, D. W. (I96I). The production of sporidesmin and sporidesmolides by Pithomyces chartarum. Journal of General Microbiology 26, 107.

Menna, M. E. Di \& Parle, J. N. (I970). Moulds on leaves of perennial ryegrass and white clover. New Zealand Journal of Agricultural Research 13, (In press).

Mortimer, P. H. \& Collins, B. S. (I968). The in vitro toxicity of the sporidesmins and related compounds to tissue-culture cells. Research in Veterinary Science 9, I36. 
Percival, J. C. \& Thornton, R. H. (I958). Relationship between the presence of fungal spores and a test for hepatotoxic grass. Nature 182, I095.

Ross, D. J. (I962). A study of the physiology of Pithomyces chartarum (Berk. \& Curt.) M. B. Ellis. 4. The influence of temperature and period of incubation on production of sporidesmin on a potatocarrot extract medium. New Zealand Journal of Science 5, 246.

Ross, D. J. \& Thornton, R. H. (I962). A study of the physiology of Pithomyces chartarum (Berk. \& Curt.) M. B. Ellis. 3. Production of toxin on some laboratory media. New Zealand Journal of Science 5, 165 . 